\title{
BMJ Open Extent and cost of inappropriate use of tumour markers in patients with pulmonary disease: a multicentre retrospective study in Shanghai, China
}

\author{
Haichen Zhang, ${ }^{1,2}$ Yunxiao Song, ${ }^{2}$ Xiong Zhang, ${ }^{3}$ Jun Hu, ${ }^{4}$ Suwei Yuan, ${ }^{1}$ Jin $\mathrm{Ma}^{1}$
}

To cite: Zhang $H$, Song $Y$, Zhang $X$, et al. Extent and cost of inappropriate use of tumour markers in patients with pulmonary disease: a multicentre retrospective study in Shanghai, China. BMJ Open 2018;8:e019051. doi:10.1136/ bmjopen-2017-019051

- Prepublication history and additional material for this paper are available online. To view these files, please visit the journal online (http://dx.doi. org/10.1136/bmjopen-2017019051).

Received 9 August 2017 Revised 30 November 2017 Accepted 11 January 2018

Check for updates

${ }^{1}$ School of Public Health, Shanghai Jiao Tong University School of Medicine, Shanghai, China

${ }^{2}$ Department of Clinical Laboratory, Shanghai Xuhui Central Hospital, Shanghai, China

${ }^{3}$ Department of Information Service, Shanghai Xuhui Central Hospital, Shanghai, China ${ }^{4}$ Department of Respiratory Medicine, Shanghai Xuhui Central Hospital, Shanghai, China

Correspondence to

Dr Jin Ma; majin@shsmu.edu.cn

\section{ABSTRACT}

Objectives The currently implemented healthcare reform in China requires substantial capital investment. Although overtreatment results in serious waste, inappropriate laboratory use is widespread, and overuse of tumour markers (TMs) has attracted increasing attention.

Design Retrospective study.

Setting The respiratory, thoracic surgery and oncology departments of three hospitals in Shanghai from 2014 to 2015.

Participants Patients with chronic obstructive pulmonary disease (COPD) and primary bronchogenic lung cancer (PLC). Based on clinical guidelines and physician experience, the criteria of suitability of TM examinations were determined, and the number, cost and proportion of inappropriate TM requests were analysed.

Results The area under the receiver operating characteristic curve for carcinoembryonic antigen+cytokeratin fragment 21-1+squamous cell carcinoma antigen+neuron-specific enolase in patients with COPD and PLC was 0.813, in accordance with the cost-effectiveness principle, indicating good clinical and health economics values. In the 2706 patients, 12496-16956 (58.27\%-79.06\%) of TM requests were inappropriate. Furthermore, the involved expense was 650200-1 014156 yuan, accounting for $7.69 \%-12.00 \%$ of examination expenses and $1.35 \%-2.11 \%$ of hospitalisation costs.

Conclusions We found that the inappropriate use of TMs was widespread for patients with pulmonary disease. Clinicians should use TMs strictly according to the guidelines to effectively manage laboratory resources and control costs.

\section{INTRODUCTION}

In 2009, the Chinese government invested $¥ 850$ billion to establish a medical security system with universal coverage, with the aim of continuously improving protection, strengthening public healthcare services and constructing primary healthcare institutions. This healthcare reform aimed to reduce the high cost of medical treatment and make it more accessible. ${ }^{1}$ However, health expenses have increased significantly
Strengths and limitations of this study

- This was a multicentre study with a large sample size (2706 cases), so our findings are likely to be representative of patients in China.

- Cost-effectiveness analysis helped identify the tumour marker combination with the lowest cost.

- Sensitivity analysis corroborated the findings of the cost-effectiveness analysis, strengthening the validity of our results.

- However, this was a retrospective study, and only tumour markers used in laboratory tests were analysed.

since 2009. The total health expense in 2014 increased by $11.0 \%$, which far exceeded the gross domestic product growth rate of $7.4 \%$.

Excessive medical treatment refers to that administered by medical staff against clinical norms and ethical guidelines that do not add value to the diagnosis and treatment of patients while increasing the cost of medical resources. In the USA alone, $16 \%$ of cases of tonsillectomy, $17 \%$ of treatment for carpal tunnel syndrome, $20 \%$ of cardiac pacemaker implantations, $27 \%$ of hysterectomy procedures and $50 \%$ of caesarean sections were shown to be unnecessary. ${ }^{2}$ Approximately $\$ 200$ billion is wasted annually on unnecessary treatment in the USA. ${ }^{3}$ Complex treatment of simple diseases, heavy use of expensive medical materials and overloose grasp of surgical indicators are not uncommon. ${ }^{4-8}$ Excessive examination would lead to false-positive outcomes, which means that patients without positive symptoms yield positive results. False positives, which are inevitable, may be excluded after further examination; however, it adversely affects the physical and mental health of patients as well as medical expenses. ${ }^{9}$ Excessive examination often leads to overdiagnosis, especially in malignant tumours. Tumours found by 
some screenings have no abnormalities. Some tumours are spontaneously apoptotic, and some of them do not cause symptoms throughout life; some may be life-threatening but do not cause health damage due to death from other diseases. Diagnosing such tumours is disadvantageous, because subsequent examinations and treatments are not necessary; instead, treatment often leads to physical and mental discomfort or may be fatal. ${ }^{10}$ Excessive examination occurs from inappropriate requests, that is, by violating clinical guidelines, medical norms or conventional diagnostic habits, and results in waste of medical resources and increased medical expenses. ${ }^{11}$ Inappropriate requests should not be implemented ${ }^{12}$ but are very common. The National Health Service has undertaken large-scale laboratory restructuring to save $£ 500$ million of annual examination expenses. ${ }^{13}$ Inappropriate requests can be effectively reduced by comprehensive intervention, including training doctors, controlling the request process and strengthening communication between the inspectors and doctors. ${ }^{14-17}$

Tumour markers (TMs) are molecules produced by tumour cells or synthesised by non-tumour cells after coming into contact with tumour cells. Although TMs are valuable in tumour diagnosis, it is important to avoid their inappropriate use in the clinical setting to prevent the inappropriate use of medical resources and the waste of medical funds.

In clinical settings, patient situations vary widely, and the severity of diseases differs considerably. Thus, it is difficult to judge whether a request for a TM test is reasonable. In clinical practice, the recommended or carefully recommended items are listed as appropriate examinations based on the disease guidelines developed by the relevant professional associations, while those not recommended are listed as inappropriate examinations. However, guides are often complex with few practical guidelines. In this study, we investigated the extent to which TMs are inappropriately used in patients with pulmonary disease and how the inappropriate use affects cost.

\section{MATERIALS AND METHODS \\ Study design and participants}

This retrospective study included inpatients in the Departments of Respiratory Medicine, Thoracic Surgery and Oncology at three Shanghai general hospitals (one grade III class A, one grade III class B and one grade II class A) from January 2014 to December 2015. The primary diagnosis on admission was acute exacerbation of chronic obstructive pulmonary disease (COPD) International Classification of Diseases version 10 (ICD-10:J44.001/J44.101) and primary lung cancer (PLC) (ICD-10:C34/D02.2). Patients with COPD were diagnosed according to the diagnostic criteria of the Guidelines for Diagnosis and Treatment of Chronic Obstructive Pulmonary Disease (2007 version) developed by the Chinese Academy of Respiratory Sciences. Patients with PLC met the Tumor Node Metastasis (TNM) staging criteria of the
International Anti-Cancer Alliance for lung cancer, and results were confirmed by pathology and imaging. All medical records were examined by two trained specialists to exclude patients with non-pulmonary diseases such as surgical, cardiovascular and cerebrovascular diseases, as well as patients who received conventional diagnosis and had a very short hospital stay. Data regarding demographics (gender and age), diagnosis on admission, disease complexity and number of diseases, clinical pathways, the number and results of commonly used TMs, hospitalisation stay, payment types and expenses involved in hospitalisation, examination and TM analysis were recorded by the hospitals. All data relevant to the study were collected from each of the hospitals by the first author.

\section{Laboratory examination and TMs}

All the three hospitals used TMs for clinical selection. The departments that had ordered the TM examinations were Respiratory Medicine (mostly for diagnosis and differential diagnosis), Thoracic Surgery (mostly for screening and evaluation of treatment effect) and Oncology (mostly for evaluation of treatment effect in patients with a definitive diagnosis who were receiving chemotherapy). We selected projects that were technically mature and had been developed with 14 TMs: alpha-fetoprotein, carcinoembryonic antigen (CEA), cancer antigen-50 (CA50), CA125, CA153, CA199, cytokeratin fragment 21-1 (CYFRA211), CA242, CA724, squamous cell carcinoma antigen (SCC), neuron-specific enolase (NSE), prostate-specific antigen (PSA), free PSA and tumour-specific growth factor. The markers were quantitatively analysed using chemiluminescence or electroluminescence, and the results of each examination were recorded.

\section{Criteria for suitability}

Based on clinical guidelines ${ }^{18} 19$ and diagnostic practices, we invited 12 physicians/technicians with advanced titles from the Departments of Respiratory Medicine, Thoracic Surgery, Oncology and Laboratory Testing to the interview. CEA is a TM associated with the severity of COPD. ${ }^{20}$ CYFRA211, NSE and SCC are markers relatively sensitive for non-small cell lung cancer, small cell lung cancer and squamous cell lung carcinoma, respectively. ${ }^{20-22}$ Therefore, the above four markers were selected as the initial screening indicators. Targeted expansion examinations could be performed if any abnormality was found. It should be mentioned that currently available serum TMs lack sensitivity and/or specificity for the early detection of cancer.

\section{Index and construction of model}

1. In cost-effectiveness analysis, the cost of the TM test (C) and its sensitivity to effect (E) were measured and used to calculate the cost-effectiveness ratio $(\mathrm{C} / \mathrm{E})$. The cost added by a $1 \%$ increase in sensitivity was 
considered the incremental cost-effectiveness ratio $(\Delta \mathrm{C} / \Delta \mathrm{E})$.

2. Sensitivity analysis: assuming that detection costs decreased by $10 \%$, the costs of different programmes with similar effects were compared.

\section{STATISTICAL ANALYSIS}

SPSS V.22.0 software was used for statistical analysis. Data are expressed as the mean $\pm \mathrm{SD}$, and Student's t-test was used for comparisons between groups. The associations of various parameters (TM expense, examination expense and hospitalisation expense) with the number of TMs, age, year of discharge, number of diagnoses and hospital stay were assessed by linear regression analysis. The performance levels of the TMs were determined by calculating the areas under the receiver operating characteristic curves (AUCs) as well as Youden index values, sensitivities and specificities. $\mathrm{P}<0.05$ was considered statistically significant.

\section{RESULTS}

\section{Baseline patient features}

This study assessed 4191 cases from 1 January 2014 to 31 December 2015 in three hospitals. After excluding patients without COPD and PLC, those without formal treatment, and those with inconsistent diagnoses on admission and discharge, a total of 2706 cases were obtained and included in the analysis. There were 1959 men and 747 women, with an average age of $74.02 \pm 11.87$ years. There were 1568 cases of COPD and 1138 cases of LC. Table 1 summarises the hospital stay, number of diseases, treatment efficacy, number of TMs, payment types and expenses associated with TM testing, examination and hospital stay.

\section{Detection performance of TMs}

We analysed the diagnostic performances of single TMs, including sensitivity, specificity and Youden index (online supplementary table 1 ). The TMs CEA (52.70\%), CYFRA211 (51.43\%), CA50 (48.94\%) and CA125 (34.08\%) showed the highest sensitivities, with Youden index values of $0.48,0.41,0.38$ and 0.31 , respectively.

As proposed by the expert committee, the Youden index values of CEA, CYFRA211, CA50 and CA125, as well as those of CEA, CYFRA211, NSE and SCC were used to perform permutations and combinations of 2-4 items, respectively. Moreover, the AUCs were calculated. TM combinations used the parallel test, which referred to various diagnostic tests. The subjects were considered patients as long as one of the tests was positive. There were 11 types of $T M \times 2$ combinations. The three $T M \times 2$ combinations with the highest AUC values were CEA+CYFRA211, CEA+NSE and CEA+SCC (AUC: 0.769, 0.764 and 0.754 , respectively). There were eight $\mathrm{TM} \times 3$ combinations, of which CEA+NSE+SCC, CEA+NSE+CYFRA211 and CEA+CYFRA211+SCC (AUC: 0.797, 0.791 and 0.789,

\begin{tabular}{ll}
\hline Table 1 & Basic data of the 2706 participants \\
\hline Data & Sum \\
\hline $\begin{array}{l}\text { Gender } \\
\text { Male }\end{array}$ & 1959 \\
\hline Female & 747 \\
\hline Age (years) & $74.02 \pm 11.87$ \\
\hline Diseases & \\
\hline COPD & 1568 \\
\hline LC & 1138 \\
\hline Hospital stay (days) & $14.14 \pm 9.16$ \\
\hline Number of diseases & $2.58 \pm 1.10$ \\
\hline Efficacy & \\
\hline Effective (\%) & 79.1 \\
\hline Ineffective (\%) & 20.9 \\
\hline Implementation of clinical & 12.4 \\
pathway (\%) & \\
\hline Number of TMs & $8.01 \pm 3.63$ \\
\hline TM expense (yuan) & $479.73 \pm 222.11$ \\
\hline Examination expense (yuan) & $3123.71 \pm 1753.12$ \\
\hline Hospitalisation expense (yuan) & $17799.35 \pm 13195.28$ \\
\hline Payment types & \\
\hline Cadre insurance (\%) & 5.9 \\
\hline Medical insurance (\%) & 81.7 \\
\hline Uninsured patients (\%) & 12.4 \\
\hline
\end{tabular}

COPD, chronic obstructive pulmonary disease; LC, lung cancer; TM, tumour marker.

respectively) had the highest AUC values. Additionally, there were two $\mathrm{TM} \times 4$ combinations. The AUC values of CEA+CYFRA211+NSE+SCC and CEA+CA50+CA125+CYFRA211 were 0.813 and 0.795 , respectively. Table 2 presents the results of combined detection by the TMs.

\section{COST-EFFECTIVENESS ANALYSIS}

TM combinations with sensitivity $>70 \%$ were selected for cost-effectiveness analysis. CEA+CA125 had the lowest cost and was therefore used as a reference. The incremental cost-effectiveness ratio $(\Delta \mathrm{C} / \Delta \mathrm{E})$ was determined by comparing other combinations with the reference value. The additional cost $(\mathrm{C})$ involved in increasing sensitivity by $1 \%$ (E) was calculated. The cost-effectiveness ratio of CEA+CA125 was the best (1.15), and the sensitivities of the remaining combinations were also improved when the cost was increased (table 3).

\section{SENSITIVITY ANALYSIS}

We then analysed how sensitivity was affected when the detection expense was decreased by $10 \%$. CEA+CA125 $\left(\mathrm{C}^{\prime} / \mathrm{E}=1.03\right)$ still had the lowest cost required by the same effects, with detection expense decreased by $10 \%$, consistent with the cost-effectiveness analysis findings (table 4). 


\begin{tabular}{ll}
\hline $\begin{array}{l}\text { Table } 2 \text { Clinical performances of tumour marker (TM) } \\
\text { combinations }\end{array}$ & AUC \\
\hline TM combination & \\
\hline TM×2 & 0.662 \\
NSE+SCC & 0.664 \\
CA50+CYFRA211 & 0.69 \\
NSE+CYFRA211 & 0.697 \\
SCC+CYFRA211 & 0.716 \\
CA125+CYFRA211 & 0.72 \\
CA50+CA125 & 0.749 \\
CEA+CA50 & 0.75 \\
CEA+CA125 & 0.754 \\
CEA+SCC & 0.764 \\
CEA+NSE & 0.769 \\
CEA+CYFRA211 & \\
TM×3 & 0.728 \\
NSE+SCC+CYFRA211 & 0.751 \\
CA50+CA125+CYFRA211 & 0.764 \\
CEA+CA50+CYFRA211 & 0.773 \\
CEA+CA50+CA125 & 0.788 \\
CEA+CA125+CYFRA211 & 0.789 \\
CEA+CYFRA211+SCC & 0.791 \\
CEA+NSE+CYFRA211 & 0.797 \\
CEA+NSE+SCC & \\
\hline TM×4 & 0.795 \\
CEA+CA50+CA125+CYFRA211 & 0.813 \\
CEA+CYFRA211+NSE+SCC & \\
\hline AUC, & \\
\hline
\end{tabular}

AUC, area under the receiver operating characteristic curves; CA50, cancer antigen-50; CEA, carcinoembryonic antigen; CYFRA211, cytokeratin fragment 21-1; NSE, neuron-specific enolase; SCC, squamous cell carcinoma antigen.

\section{Number and cost of inappropriate TMs}

Based on maximum AUC, CEA+CYFRA211, CEA+CYFRA211+NSE and CEA+CYFRA211+NSE+SCC were selected as criteria for suitability tests of the $2-4 \times \mathrm{TM}$ combinations. Then, the number and cost of the TMs, as well as examination and hospitalisation expenses for inappropriate TM requests, were assessed. According to the suitability criteria and the actual testing situation, the number and proportion of inappropriate TMs were calculated (table 5).

A total of 21446 TM detections, costing 1299344 yuan, were performed for the 2706 cases. According to the CEA+CYFRA211 standard, 16956 of these requests (79.06\% of all TM requests) were inappropriate and cost 1014156 yuan, accounting for $12.00 \%$ and $2.11 \%$ of examination and hospitalisation expenses, respectively. Based on CEA+CYFRA211+NSE as the standard, there were 14677 inappropriate TM requests $(68.44 \%$ of all TM requests), and the involved cost was 868300 yuan, accounting for $10.27 \%$ and $1.80 \%$ of the examination and hospitalisation expenses, respectively. Based on CEA+CYFRA211+NSE+SCC as the standard, there were 12496 (58.27\% of all TM requests) inappropriate TM requests costing 650200 yuan, accounting for $7.69 \%$ and $1.35 \%$ of the examination and hospitalisation expenses, respectively.

\section{Factors influencing the medical expenses}

We obtained hospitalisation and examination expenses as well as payment types for all patients. By querying medical records, the numbers of diseases and combined diseases, gender and years in hospital were obtained. TM expenses could be calculated by the number and cost of TM detections. We found that hospital stay, examination expense and TM expense were affected by many factors. Hospitalisation and examination expenses were higher in

\begin{tabular}{|c|c|c|c|c|}
\hline Combinations & Cost (C) (yuan) & Effectiveness (E) \% & C/E & $\Delta \mathrm{C} / \Delta \mathrm{E}$ \\
\hline $\mathrm{CEA}+\mathrm{CA} 125$ & 87 & 75.85 & 1.15 & 0.00 \\
\hline $\mathrm{CEA}+\mathrm{CA} 211$ & 132 & 77.03 & 1.71 & 20.68 \\
\hline $\mathrm{CA} 50+\mathrm{CA} 211$ & 155 & 75.20 & 2.06 & 194.20 \\
\hline $\mathrm{CEA}+\mathrm{CA} 50+\mathrm{CA} 125$ & 142 & 84.08 & 1.69 & 5.96 \\
\hline CEA+CA50+CA211 & 187 & 88.27 & 2.12 & 7.45 \\
\hline $\mathrm{CEA}+\mathrm{CA} 125+\mathrm{CA} 211$ & 187 & 84.86 & 2.20 & 9.99 \\
\hline $\mathrm{CA} 50+\mathrm{CA} 125+\mathrm{CA} 211$ & 210 & 83.65 & 2.51 & 13.97 \\
\hline $\mathrm{CEA}+\mathrm{CA} 50+\mathrm{CA} 125+\mathrm{CA} 211$ & 242 & 92.27 & 2.62 & 8.90 \\
\hline $\mathrm{CEA}+\mathrm{NSE}+\mathrm{SCC}$ & 196 & 76.82 & 2.55 & 55.46 \\
\hline $\mathrm{CEA}+\mathrm{NSE}+\mathrm{CA} 211$ & 196 & 84.08 & 2.33 & 11.81 \\
\hline $\mathrm{CEA}+\mathrm{SCC}+\mathrm{CA} 211$ & 232 & 83.75 & 2.77 & 16.29 \\
\hline $\mathrm{NSE}+\mathrm{SCC}+\mathrm{CA} 211$ & 264 & 76.19 & 3.46 & 131.80 \\
\hline $\mathrm{CEA}+\mathrm{NSE}+\mathrm{SCC}+\mathrm{CA} 211$ & 296 & 88.74 & 3.34 & 15.05 \\
\hline
\end{tabular}

CA50, cancer antigen-50; CEA, carcinoembryonic antigen; NSE, neuron-specific enolase; SCC, squamous cell carcinoma antigen. 
Table 4 Outcomes of sensitivity analysis

\begin{tabular}{|c|c|c|c|c|}
\hline Combinations & Effectiveness (E) \% & $\mathbf{C}^{\prime}$ & $\mathbf{C}^{\prime} / \mathbf{E}$ & $\Delta \mathrm{C}^{\prime} / \Delta \mathrm{E}$ \\
\hline $\mathrm{CEA}+\mathrm{CA} 125$ & 75.85 & 78.3 & 1.032301 & 0 \\
\hline $\mathrm{CEA}+\mathrm{CA} 211$ & 77.03 & 118.8 & 1.542329 & 34.42736 \\
\hline $\mathrm{CEA}+\mathrm{CA} 50+\mathrm{CA} 125$ & 84.08 & 127.8 & 1.519992 & 6.015012 \\
\hline $\mathrm{CEA}+\mathrm{CA} 50+\mathrm{CA} 211$ & 88.27 & 168.3 & 1.906657 & 7.246567 \\
\hline $\mathrm{CA} 50+\mathrm{CA} 125+\mathrm{CA} 211$ & 83.65 & 189 & 2.259362 & 14.18877 \\
\hline $\mathrm{CEA}+\mathrm{CA} 50+\mathrm{CA} 125+\mathrm{CA} 211$ & 92.27 & 217.8 & 2.360531 & 8.497098 \\
\hline $\mathrm{CEA}+\mathrm{NSE}+\mathrm{SCC}$ & 76.82 & 176.4 & 2.296412 & 101.6071 \\
\hline $\mathrm{CEA}+\mathrm{NSE}+\mathrm{CA} 211$ & 84.08 & 176.4 & 2.09802 & 11.92084 \\
\hline $\mathrm{CEA}+\mathrm{SCC}+\mathrm{CA} 211$ & 83.75 & 208.8 & 2.493112 & 16.51739 \\
\hline
\end{tabular}

CA50, cancer antigen-50; CEA, carcinoembryonic antigen; NSE, neuron-specific enolase; SCC, squamous cell carcinoma antigen.

institution B, but TM expenses were significantly lower, compared with the values obtained in A and C. Hospitalisation and examination expenses of COPD were higher than those of lung cancer, but TM expenses were lower among patients with COPD. Hospitalisation and examination expenses were higher in patients with $\geq 4$ diseases than in those with 1-3 diseases. Male inpatients incurred higher expenses compared with female counterparts. Expenses were higher in 2015 than in 2014, even after taking into account the inflation factor. However, the difference was most significant among payment types. Hospitalisation and examination expenses, as well as TM use in patients with cadre insurance were all higher compared with those using medical insurance; the medical insurance group showed higher values than uninsured patients (table 6). Cadre insurance, used by government officials, covers all medical expenses, and the patients pay no fees for their examination or treatment, including surgery, medications, laboratory tests and imaging. However, patients with medical insurance pay

\begin{tabular}{|c|c|c|c|}
\hline TM & $\begin{array}{l}\mathrm{TM}^{\star} 2 \\
\text { standards }\end{array}$ & $\begin{array}{l}\mathrm{TM}^{\star 3} \\
\text { standards }\end{array}$ & $\begin{array}{l}\mathrm{TM}^{\star 4} \\
\text { standards }\end{array}$ \\
\hline Number & 16956 & 14677 & 12496 \\
\hline Amount of money & 1014156 & 868300 & 650200 \\
\hline $\begin{array}{l}\text { Proportion in the } \\
\text { number of TM (\%) }\end{array}$ & 79.06 & 68.44 & 58.27 \\
\hline $\begin{array}{l}\text { Proportion in } \\
\text { the examination } \\
\text { expense }(\%)\end{array}$ & 12.00 & 10.27 & 7.69 \\
\hline $\begin{array}{l}\text { Proportion in the } \\
\text { hospitalisation } \\
\text { expense (\%) }\end{array}$ & 2.11 & 1.80 & 1.35 \\
\hline
\end{tabular}

TM, tumour marker. a deductible before the insurance kicks in, in addition to a copayment of about $10 \%-20 \%$. Therefore, patients on medical insurance likely care more about their health bills.

Linear regression indicated that the number of TMs, age, year of discharge, number of diagnoses and hospital stay were associated with $\mathrm{TM}$ cost $($ all $\mathrm{P}<0.05)$; these parameters were also significantly associated with examination expense, except for year of discharge $(\mathrm{P}=0.141)$ as well as TM expense $(\mathrm{P}=0.139)$. Of all the parameters assessed, only the number of TMs and TM expense showed no significant associations with hospitalisation cost $(\mathrm{P}=0.124$ and 0.230 , respectively; online supplementary table 2$)$.

\section{DISCUSSION}

Previous studies have reported that overuse of TMs increases medical expenses, with adverse health consequences. ${ }^{2324}$ For a long time, it has been difficult to achieve effective control of TM overuse. This was primarily due to lack of standards and tools for suitability assessment. In this study, indications for appropriate TM use were formed based on clinical guidelines of lung diseases as well as expert consensus.

Sensitivities and specificities of single TMs differed across tumours. For lung diseases, TMs with the highest sensitivities and specificities should be chosen, including CEA. However, the likelihood of misdiagnosis is higher when a single TM is used, and combined detection can significantly improve sensitivity. Therefore, we selected TM combinations with the highest clinical values according to their AUCs. The AUC values were highest for CEA+CYFRA211+SCC (0.797) and CEA+CYFRA211+SCC+NSE (0.813).

In addition to the diagnostic performances of TM combinations, cost should also be considered by health 


\begin{tabular}{|c|c|c|c|}
\hline & Hospitalisation expense & Examination expense & TM expense \\
\hline \multicolumn{4}{|l|}{ Medical institutions } \\
\hline A & $17649.59 \pm 13157.48$ & $3327.34 \pm 1841.07$ & $533.00 \pm 156.97$ \\
\hline B & $20773.05 \pm 14491.80^{*}$ & $3504.22 \pm 1689.29^{*}$ & $94.83 \pm 73.89^{*}$ \\
\hline C & $17572.57 \pm 12989.82$ & $2688.04 \pm 1499.85^{\star}$ & $447.21 \pm 265.89^{\star}$ \\
\hline \multicolumn{4}{|l|}{ Diseases } \\
\hline COPD & $198343 \pm 14950.69$ & $3499.85 \pm 1948.87$ & $463.02 \pm 195.95$ \\
\hline LC & $14826.51 \pm 9606.45^{\star}$ & $2567.94 \pm 1243.67^{\star}$ & $517.44 \pm 236.13^{*}$ \\
\hline \multicolumn{4}{|l|}{ Number of diseases } \\
\hline$\geq 4$ & $24966.67 \pm 21991.41$ & $3978.08 \pm 2127.45$ & $440.13 \pm 271.96$ \\
\hline $1-3$ & $16935.80 \pm 11599.83^{\star}$ & $3011.30 \pm 1579.39 *$ & $493.48 \pm 209.84^{\star}$ \\
\hline \multicolumn{4}{|l|}{ Gender } \\
\hline Male & $18083.13 \pm 13521.05$ & $3137.43 \pm 1748.90$ & $495.06 \pm 217.94$ \\
\hline Female & $16600.79 \pm 12078.63^{*}$ & $2994.49 \pm 1725.99^{*}$ & $463.87 \pm 208.66^{\star}$ \\
\hline \multicolumn{4}{|l|}{ Year in hospital } \\
\hline 2014 & $16774.08 \pm 12720.50$ & $3015.10 \pm 1649.32$ & $493.76 \pm 211.94$ \\
\hline 2015 & $18746.84 \pm 13580.36^{\star}$ & $3196.79 \pm 1844.98^{*}$ & $477.83 \pm 220.16^{\star}$ \\
\hline \multicolumn{4}{|l|}{ Payment types } \\
\hline Cadre insurance & $34244.17 \pm 23731.75$ & $5013.04 \pm 3497.35$ & $656.68 \pm 98.1$ \\
\hline Medical insurance & $17260.65 \pm 11732.37^{*}$ & $3102.14 \pm 1496.90 *$ & $485.04 \pm 209.80$ * \\
\hline Uninsured patients & $12453.23 \pm 7703.18^{\star}$ & $2155.37 \pm 1118.00^{*}$ & $414.44 \pm 249.43^{\star}$ \\
\hline
\end{tabular}

${ }^{*} \mathrm{P}<0.05$.

COPD, chronic obstructive pulmonary disease; TM, tumour marker.

managers. CEA is a commonly used parameter for determining cost efficiency. Our results revealed that CEA+CA125 required the lowest additional cost to increase detection sensitivity by $1 \%$. Based on the principle of high quality and low price of health economics, sensitivity analysis was carried out. When the test cost was reduced by $10 \%$, the best effects were found with CEA+CA125. From the clinical point of view, doctors may be more inclined to use CEA+CYFRA211 due to its higher AUC compared with CEA+CA125 (0.769 vs 0.749 ), with the former more in line with diagnosis and treatment requirements despite its relatively higher cost (132 yuan vs 87 yuan). The expert committee recommended using CEA+CYFRA211+SCC+NSE as it had the highest AUC (0.813).

According to the present survey, approximately $58.27 \%-79.06 \%$ of all requests for TMs were inappropriate, and cost 650200-1 014156 yuan, accounting for $7.69 \%-12.00 \%$ and $1.35 \%-2.11 \%$ of examination and hospitalisation expenses, respectively. This is an astonishing waste of medical resources, but its effective control may also significantly reduce medical expense. Clinical pathway management may be medically effective, while a reasonable payment type is also an important means to control cost. On one hand, under the fee-for-service mode, full payment (eg, cadre insurance) is more likely to incur supplier-induced demands, resulting in the waste of medical resources and increased medical expense. On the other hand, out-of-pocket payment would expose more patients to the pressure of medical expenses. However, medical insurance based on burden-sharing at a certain proportion will divide the cost among the three parties, including medical institutions, patients and insurance companies; this would ensure a reasonable distribution of medical quality, safety and cost, leading to an optimal use of resources without waste.

In this study, CEA, CYFRA211, CA125 and CA50 showed the highest sensitivities, not in total agreement with the expert consensus, which selected CEA, CYFRA211, NSE and SCC. This may be because NSE is relatively sensitive to small cell lung cancer, while SCC is sensitive to squamous cell carcinoma, with their sensitivities to undifferentiated lung cancer relatively low. To overcome the limitations of single TM detection, we used combination diagnostic experiments, which are known to improve the diagnostic value. This study demonstrated that CEA+CYFRA211, CEA+CYFRA211+NSE and CEA+211+NSE+SCC had higher AUCs, suggesting that their clinical values were high, which also strongly supported the previous expert consensus.

A comprehensive analysis of each medical expense showed that TM expenses were affected by the number of TMs, age, year of discharge, number of diagnoses and hospital stay. Examination costs were affected by age, 


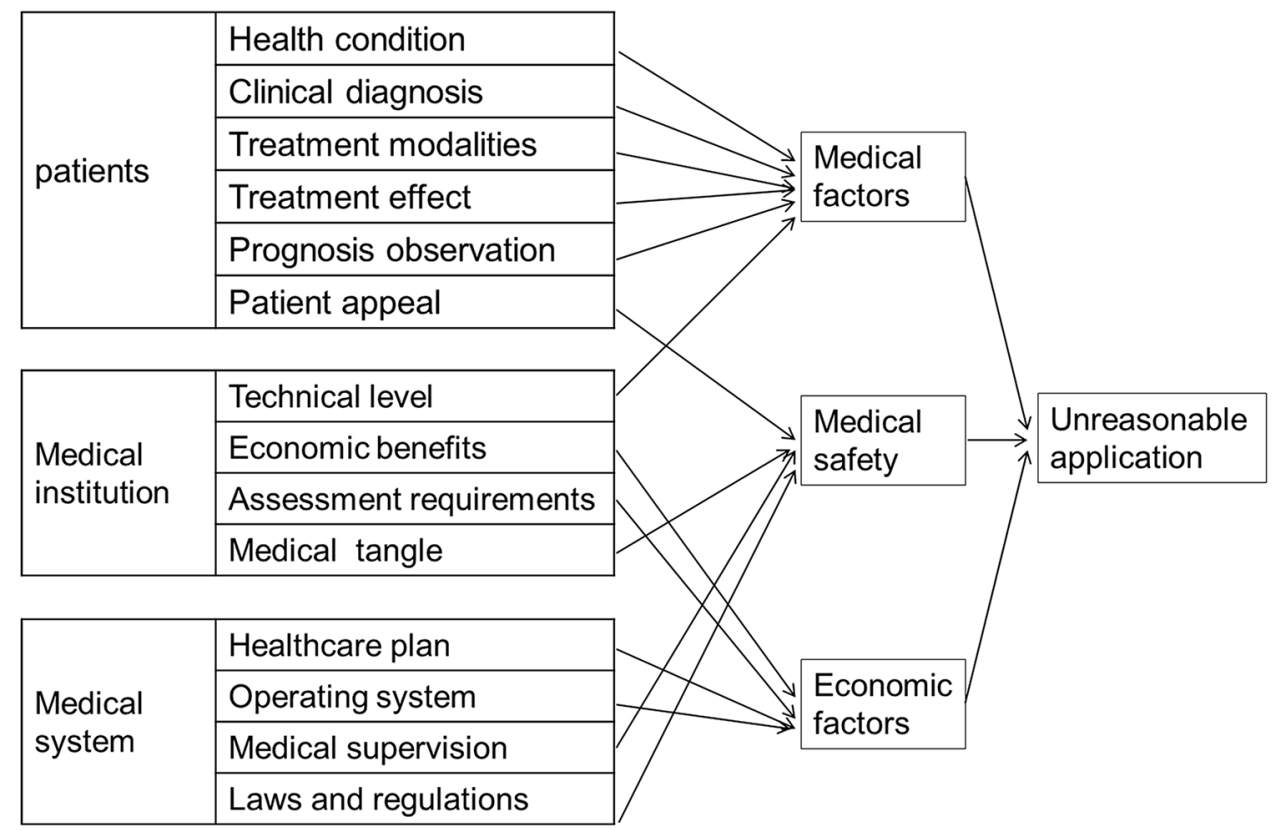

Figure 1 An information-motivation-behavioural skills (IMB) model of inappropriate requests segregated according to the patient, medical institution and system levels. As shown in the figure, various factors contribute to inappropriate requests.

number of diagnoses, hospital stay and TM expense. Hospitalisation expense was affected by age, examination expense, hospital stay, year of discharge and number of diagnoses. Medical expenses differed across medical facilities. TM expenses of institution B were lower, maybe because it used more $(62.5 \%)$ clinical pathway management. Disease complexity on admission (number of diseases: $\leq 3$ and $>4$ ) was also an important factor. Hospital stay and examination expenses increased with disease complexity, while TM expenses declined. Lung diseases with higher complexity inevitably lead to increased medical and examination expenses, while the progressive decrease of TM expenses may be due to the transfer of diagnostic and treatment focus caused by multiple combined respiratory failures. Additionally, men incurred higher medical expenses than women, because men are more likely to have multiple disease ${ }^{25-27}$ and poorer lifestyles (eg, men are more likely to be smokers) compared with women. Thus, the health condition of men is likely to be inferior to that of women, and their average life expectancy is also lower than that of women. ${ }^{28}$ The payment type was an important factor. The higher the proportion of reimbursement, the higher the medical expense, which was closely related to different cost sensitivities of patients with different payment types. In summary, the medical expense increases with disease duration and complexity as well as duration of hospital stay. Although we established an information-motivation-behavioural skills model, it was still difficult to determine the factors involved and their degrees of involvement (figure 1).

This study had limitations. We assessed only TMs used in laboratory tests, but not the suitability of other laboratory tools and the overall medical model. However, our study revealed that CEA+CYFRA211, CEA+CYFRA211+NSE and CEA+211+NSE+SCC had high AUCs and consequently high clinical values. A broader and more in-depth study based on clinical guidelines and physician experience should be conducted to determine other ways of improving cost-effectiveness and preventing the overuse of clinical tests.

In conclusion, inappropriate TM use was found to be widespread among patients with pulmonary diseases. Interestingly, a higher proportion of reimbursement was associated with higher medical expenses. Effective use of clinical pathway management resulted in lower TM expenses. Clinicians should use TMs strictly according to the guidelines to effectively manage laboratory resources and control costs.

Contributors $\mathrm{HZ}$, YS and JM carried out the studies, participated in data collection and drafted the manuscript. XZ and $\mathrm{JH}$ performed the statistical analysis and participated in study design. SY helped draft the manuscript. All authors read and approved the final manuscript.

Funding This study was supported by the Project of the Shanghai Health and Family Planning Commission (No. 201540238).

Competing interests None declared.

Patient consent Obtained.

Ethics approval The study protocol was approved by the Ethics Committee of Shanghai Xuhui Central Hospital.

Provenance and peer review Not commissioned; externally peer reviewed.

Data sharing statement Extra data can be accessed via the Dryad data repository at http://datadryad.org/ with the doi: 10.5061/dryad.nb3r0.

Open Access This is an Open Access article distributed in accordance with the Creative Commons Attribution Non Commercial (CC BY-NC 4.0) license, which permits others to distribute, remix, adapt, build upon this work non-commercially, and license their derivative works on different terms, provided the original work is properly cited and the use is non-commercial. See: http://creativecommons.org/licenses/by-nc/4.0/ 
(c) Article author(s) (or their employer(s) unless otherwise stated in the text of the article) 2018. All rights reserved. No commercial use is permitted unless otherwise expressly granted.

\section{REFERENCES}

1. Yip W, Hsiao W. China's health care reform: A tentative assessment. China Economic Review 2009;20:613-9.

2. Robet G. Supplier induced demand: some empirical evidence and implication. The economics of health and medical care. New York: Healstead Press, 1974:162-73.

3. Hoffman JR, Cooper RJ. Overdiagnosis of disease: a modern epidemic. Arch Intern Med 2012;172:1123-4.

4. Berwick DM, Hackbarth AD. Eliminating waste in US health care. JAMA 2012;307:1513-6.

5. Stergiopoulos K, Brown DL. Initial coronary stent implantation with medical therapy vs medical therapy alone for stable coronary artery disease: meta-analysis of randomized controlled trials. Arch Intern Med 2012;172:312-9.

6. Boden WE. Mounting evidence for lack of PCI benefit in stable ischemic heart disease : what more will it take to turn the tide of treatment?: comment on "initial coronary stent implantation with medical therapy vs medical therapy alone for stable coronary artery disease". Arch Intern Med 2012;172:319-21.

7. Patel MR, Peterson ED, Dai D, et al. Low diagnostic yield of elective coronary angiography. N Engl J Med 2010;362:886-95.

8. Luo XL, Zhang WY. Obstetrical disease spectrum in China: an epidemiological study of 111,767 cases in 2011. Chin Med $J$ 2015;128:1137-46.

9. Ong MS, Mandl KD. National expenditure for false-positive mammograms and breast cancer overdiagnoses estimated at $\$ 4$ billion a year. Health Aff 2015;34:576-83.

10. Woloshin S, Schwartz LM, Black WC, et al. Cancer screening campaigns-getting past uninformative persuasion. N Engl J Med 2012;367:1677-9

11. Hauser RG, Shirts BH. Do we now know what inappropriate laboratory utilization is? An expanded systematic review of laboratory clinical audits. Am J Clin Pathol 2014;141:774-83.

12. Fryer AA, Smellie WS. Managing demand for laboratory tests: a laboratory toolkit. J Clin Pathol 2013;66:62-72.

13. Report of the Second Phase of the Review of NHS Pathology Service in England. Chaired by Lord Carter of Coles. Secondary Report of the Second Phase of the Review of NHS Pathology Service in England. Chaired by lord carter of coles. http://www.dh.gov.uk/en/ Publicationsandstatistics/Publications/PbulicationsPolicyAndGuid ance/DH_091985
14. Baricchi R, Zini M, Nibali MG, et al. Using pathology-specific laboratory profiles in clinical pathology to reduce inappropriate test requesting: two completed audit cycles. BMC Health Serv Res 2012;12:187.

15. Smellie WS. Demand management and test request rationalization. Ann Clin Biochem 2012;49(Pt 4):323-36.

16. Levick DL, Stern G, Meyerhoefer CD, et al. "Reducing unnecessary testing in a CPOE system through implementation of a targeted CDS intervention". BMC Med Inform Decis Mak 2013;13:43.

17. Bareford D, Hayling A. Inappropriate use of laboratory services: long term combined approach to modify request patterns. $B M J$ 1990;301:1305-7.

18. Ettinger DS, Wood DE, Akerley W, et al. NCCN guidelines insights: non-small cell lung cancer, version 4.2016. J Natl Compr Canc Netw 2016;14:255-64.

19. Global Strategy for the Diagnosis, Management and Prevention of COPD, Global Initiative for Chronic Obstructive Lung Disease (GOLD) Secondary Global Strategy for the Diagnosis, Management and Prevention of COPD. Global Initiative for Chronic Obstructive Lung Disease. 2017. http://goldcopd.org

20. Barouchos N, Papazafiropoulou A, lacovidou N, et al. Comparison of tumor markers and inflammatory biomarkers in chronic obstructive pulmonary disease (COPD) exacerbations. Scand J Clin Lab Invest 2015;75:126-32.

21. Molina R, Filella X, Augé JM, et al. Tumor markers (CEA, CA 125, CYFRA 21-1, SCC and NSE) in patients with non-small cell lung cancer as an aid in histological diagnosis and prognosis. Comparison with the main clinical and pathological prognostic factors. Tumour Biol 2003;24:209-18.

22. Barlési F, Gimenez C, Torre JP, et al. Prognostic value of combination of Cyfra 21-1, CEA and NSE in patients with advanced non-small cell lung cancer. Respir Med 2004;98:357-62.

23. Ramsey SD, Henry NL, Gralow JR, et al. Tumor marker usage and medical care costs among older early-stage breast cancer survivors. J Clin Oncol 2015;33:149-55.

24. Han PK, Klabunde CN, Noone AM, et al. Physicians' beliefs about breast cancer surveillance testing are consistent with test overuse. Med Care 2013;51:315-23.

25. Case A, Paxson C. Sex differences in morbidity and mortality. Demography 2005;42:189-214.

26. Poortinga $W$. The prevalence and clustering of four major lifestyle risk factors in an English adult population. Prev Med 2007:44:124-8.

27. von Bothmer MI, Fridlund B. Gender differences in health habits and in motivation for a healthy lifestyle among Swedish university students. Nurs Health Sci 2005;7:107-18.

28. Barford A, Dorling D, Davey Smith G, et al. Life expectancy: women now on top everywhere. BMJ 2006;332:808. 